Article

\title{
The Sustainable Existence of China's Bicycle-Sharing Market: To Oversupply or to Disappear
}

\author{
Xi Chen ${ }^{1, *}$, Qixing $\mathrm{Qu}^{2}$, Ming-Hsiang Chen ${ }^{3} \mathbb{C}$, Shaofen Fang ${ }^{1}$ and Yi Cheng ${ }^{1}$ \\ 1 School of Business and Tourism Management, Yunnan University, Kunming 650091, China; \\ fangshaofenaha@163.com (S.F.); camillacy@163.com (Y.C.) \\ 2 School of Information, University of International Business and Economics, Beijing 100029, China; \\ qqxing@uibe.edu.cn \\ 3 School of Hospitality Business Management, Carson College of Business, Washington State University, \\ Pullman, WA 99164-4742, USA; ming-hsiang.chen@wsu.edu \\ * Correspondence: Chenxi1231@ynu.edu.cn; Tel.: +86-0871-65034152
}

Received: 18 October 2018; Accepted: 12 November 2018; Published: 15 November 2018

check for updates

\begin{abstract}
Most cities in China benefit from having a commercial and public bicycle-sharing system. However, the bicycle-sharing markets still face unbalanced development problems, i.e., initial rapid expansion in most areas, and a recent disappearance in some local areas. Thus, the economic features and rules of this market need further exploration to introduce better management measures. Based on agent-based modeling, the current paper stimulated the interactions between supply and demand with two models to illuminate the supply characteristics of the bicycle-sharing market. The main findings included the following: (1) the bicycle-sharing market is governed by a set of objective laws which naturally require an oversupply, meaning that the attainment of a high level of user satisfaction depends on high supply; (2) based on each customer's tolerance level, there is a supply density threshold that determines the existence and disappearance of the market; and (3) the width and elasticity of the supply density threshold are influenced by the tolerance of the customers, which, in turn, reflects their values and attitudes. The current research is a preliminary exploration of the interactive characteristics of supply and demand in the bicycle-sharing market. We believe that the current paper provides insights and implications to illuminate the law of existence in the bicycle-sharing market. It also includes a discussion on the sustainable development of the bicycle-sharing market in China.
\end{abstract}

Keywords: bicycle-sharing market; supply characteristics; agent-based modeling; tolerance of the customers

\section{Introduction}

China is suffering from the severe negative consequences of high private vehicle usage in its large and densely populated cities [1]. The innovative mobility solution of bicycle-sharing, which is now present in most of China's cities, made it easier for residents to move around, relieving the pressure of public transport. The sharing economy is said to be built on the concept of collaborative consumption [2,3], where these practices became increasingly popular in recent years $[4,5]$. The principle of bicycle-sharing is simple: individuals use bicycles on an "as-needed" basis without the costs and responsibilities of bicycle ownership [6].

In China, bicycle-sharing is both a model of economic development and an emerging business model [7]. It is a kind of sharing economy, with a business model that favors collaboration between consumer and producer, primarily using technology and in which a reciprocal relationship with the objectives of each party is maintained [8]. Like car-sharing services, bicycle-sharing is also 
a traffic-sharing economy business mode $[9,10]$. According to the latest census data, China has an urban population of 220 million people, which is a huge potential market. It is estimated that an annual potential market size of 28.1 billion renminbi (RMB) can be generated from the bicycle-sharing industry.

However, while creating significant economic and social benefits, the bicycle-sharing market still faces a series of problems including a high rate of bicycle damage, disordered parking, difficulty with the security of deposits, and cut-throat competition [11]; up to now, there are more than 30 competitors in the cities of China, such as Mobike, OFO (The band of a bicycle-sharing company), Pay-Pal Bicycle, and more. These issues are not conducive to the sustainable development of the bicycle-sharing market. Potential equilibrium points exist in the bicycle-sharing market [12], such as number and competition of market participants, quantity expansion, urban environment capacity, profit, and social responsibility. Once the critical point is broken, an urban problem develops. From the overwhelming initial rapid expansion of bicycle-sharing to its disappearance in some local areas, the economic logic behind this needs further exploration.

The difference between sharing and traditional economies lies in fitting a model of demand and supply. Bicycle-sharing is also a special ecosystem service (ES) that can be described with demand and supply interactions [13]. However, several questions remain unanswered. Firstly, does the mode of interaction between demand and supply in the bicycle-sharing market present special economic laws? Secondly, why is the proportion of damaged bicycles so high in the bicycle-sharing industry? Lastly, why does a critical point exist in such a manner that most cities in China with bicycle-sharing face the problem of oversupply or disappearance? The explanation and exploration of the basic economic problems in sharing bicycles are still in the grouping stage [14]. To better explain the law and solve realistic problems, these problems should be investigated further. Their development patterns should be clarified by exploring the law of interaction between supply and demand.

A long list of the literature discussed the sustainability of the bicycle-sharing industry. The psychological and cultural factors of sustainability practices and consumer use were confirmed, as were the social norms and social context in which the sustainability practices and consumers are embedded $[15,16]$. The sustainable usage of bicycle-sharing should seek an effective way of satisfying a demand for transportation [17] to improve the efficiency and service quality of the bicycle-sharing market [18-20], i.e., its perceived functional, conditional, green, and social values [19].

The key motivators for individual users and the bicycle-sharing market in general lie in its economic benefits, rather than the potential for the sustainable development of the sharing market [2]. The different degrees of overabundance, high waste, and destruction in the bicycle-sharing market in different parts of China can already be seen from relevant reports. Regardless of the increasing amount of doubt and criticism, the product-sharing economic mode remains a promising mode of resource conservation for the future [21]. Therefore, it is necessary to quantify the design of reasonable policies and thorough governance of all relevant platforms.

The theoretical contribution of this paper lies in the preliminary exploration of the interactive characteristics of supply and demand in the bicycle-sharing market. The objective was to illuminate the law of economics behind the high proportion of damaged goods and oversupply in this sector. We argue that a focus on market contexts is necessary to attain an understanding of supply and demand. Specifically, we draw on the perspective of the bicycle-sharing market to develop a dynamic model of interactions between supply and demand. We formalize these ideas in a basic agent-based model (ABM) and use it to answer questions on two extension models. The practical implications of this paper focus on solutions and suggestions for the sustainability of the bicycle-sharing market and how the relevant departments of the government and industries should cope with these challenges.

The structure of the paper is as follows: Section 2 introduces the theory basis and research methods. Section 3 proposes the model framework, and introduces the interaction rules and decision mechanisms of the agents. Section 4 describes the analysis and discussion of the simulation results. Finally, Section 5 summarizes the conclusions of the study, as well as suggestions for industrial participants and policy-makers, while also suggesting further research themes. 


\section{Theory Basis and Research Methods}

\subsection{Property Rights of the Bicycle-Sharing Market}

The sharing economy has a strong intellectual tradition from lifestyle and social movement, consumption practice, and the sharing paradigm [22]. Compared with the traditional economy model, the most typical characteristic of the sharing economy is the change of the property rights structure. In a traditional physical economy, ownership and the right to use things are integrated. However, in the sharing economy, they are separated. By means of the internet and information technology, the right to use and specific demands of things can be matched accurately. Through transferring the right to use of idle resources, efficient resource collocation and significant economic and social benefits can be realized. These are the advantages of the sharing economy. In the sharing economy, both social innovations and a complementary and equally valued strategy of sustainable consumption are required: goods must be used for a longer period, and services that support collaborative consumption (CC) patterns must be extended. "Using rather than owning" strategies such as product sharing have the potential to conserve resources [21].

The global economic downturn led us to re-examine the relationship of wealth and consumption. The pressure brought by economic hardship forced us to further explore the existing assets owned by different groups, thus promoting the idea that the "right to use is more important" [23]. The separation of ownership and the right to use are the principal characteristics of the sharing economy. Different types of sharing economies demonstrate special economic laws. However, there are significant differences in the economic laws behind the sharing economic patterns for different types of products and services. The two inherent characteristics of shared goods determine the differences.

The first of these is the degree of accuracy in matching shared goods with the users who require them, i.e., whether the needs of the users for the shared goods are personalized or not. With a high degree of personalization, the shared goods can be shared through platforms to match the supply with the requisitioning party. The requisitioning party takes the initiative to search actively according to their demands. The supply side adjusts their products and services in line with these demands. Thus, products and services with a low accuracy of demand might be homological. To a large degree, users do not have to spend a lot of time and energy to look for what they want. Instead, they can consume them conveniently in actual work and life.

The second characteristic relates to the transfer of the rights of disposal, i.e., to improve the utilization ratio of idle goods and effectively allocate resources to the supply and requisitioning parties. However, as shown in Figure 1, for different shared goods, the degree of transferal by the actual property owners is different. For instance, in home sharing, those who have the right of habitation cannot enjoy the right of disposal of the house. However, with its low accuracy of demand matching, bicycle-sharing has a relatively high transferability of the right of disposal.

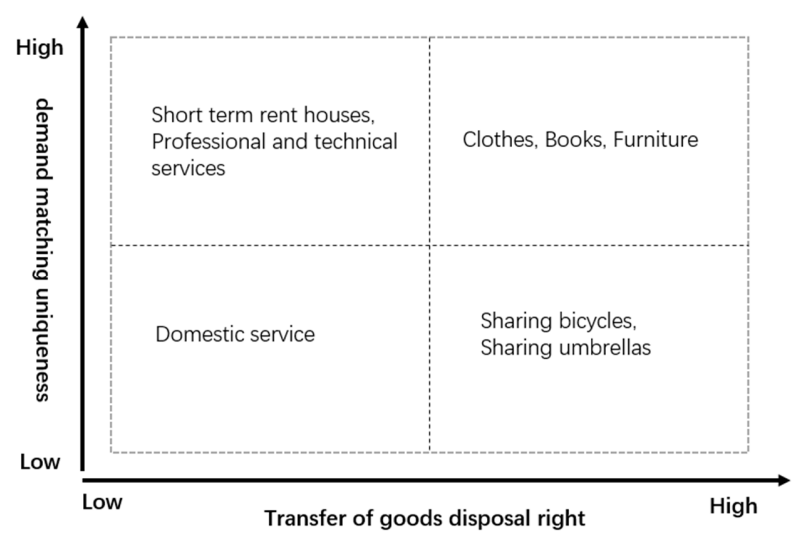

Figure 1. Product type space formed from two dimensions: degree of demand matching uniqueness ( $Y$-axis), and transfer of goods disposal right when sharing (X-axis). 
As shown in Figure 1, based on the combination of the high level and low level of these two characteristics, we divide the market of sharing economy into four quadrants, which can be used to divide some common market characteristics of sharing economies. Unlike the Didi and Uber's C2C model, bicycle-sharing currently uses the B2C model (C2C describes the electronic commerce business relations between individuals and individuals. $\mathrm{C}$ refers to consumers, $\mathrm{C} 2 \mathrm{C}$ means consumer to consumer; $\mathrm{B} 2 \mathrm{C}$ means business to consumer). Therefore, some hold the view that bicycle-sharing is not part of the sharing economy with its earlier appearance. However, as the right of use is shared by several users, it still largely falls into the category of a sharing economy [24].

Due to the high degree of transferability of disposal rights and homological demands, bicycle-sharing naturally has the characteristic described by Hardin as a tragedy of the commons - things shared by many people are barely protected and are most likely to be damaged [25]. Coase et al. (1994) pointed out that, in the tragedy of public lands, public land refers to a kind of resource or property that is shared by the public. Everyone enjoys the right of use, but no one can prevent others from using it [26]. People who carry out activities on public land do not consider the impacts of their activities on others, which leads to the exhaustion of resources due to the excessive use of public land. According to properties of public goods of sharing bicycles causing a higher possibility of being damaged, the proportion of bicycles damaged in China is high with an OFO damaged rate of $20 \%$ and a Mobike rate of about $10 \%$ (OFO is the brand of small yellow bicycle, which is the earliest bicycle-sharing platform without fixed stops in China's market, and its business is spread all over the world).

Another negative effect of the tragedy of the commons is free-riding behavior (free-riding behavior mainly refers to the misuse of the shared bicycles, which produces a negative image of the service). It is reported that some people disassembled parts of the shared bicycles and installed them onto their own private bicycles, or even locked the bicycles and claimed them as their own. The high attrition rate brought by the tragedy of the commons necessitated continuous investment from the industry operators to maintain the basic supply of the market.

\subsection{Stimulating Interaction between Demand and Supply}

Due to the many rational assumptions that are inconsistent with the real laws, optimal or equilibrium solutions from theoretical models were increasingly questioned. Therefore, some researchers put forward new approaches to remedy the shortage in traditional economics research. Agent-based computational economics represent an evolutionary system composed of multiple independent and interactive agents; it is also a computational study that completes modeling for the whole economic system $[27,28]$. A social economic system contains many adaptive and interactive economic agents, which are mutually influencing to form typical rules in a macro-economic system [29]. Due to the interactions of micro-individuals in agent-based modeling [30], the macroeconomic law emerged from the bottom up. Agent-based modeling (ABM) is a computational approach that investigates macro-level complex emergent phenomena through simulations of the collective micro-behaviors of autonomous agents [31].

The dynamic and constantly mutable ACE model is capable of properly simulating the economic system [32] using both theoretical and practical perspectives [33,34]. The ABM approach is applied in many fields and completely showed its ability to analyze social problems [35,36]. It can also simulate the matching and interactive relationship between demand and supply in the sharing economy, along with the objective laws that are different from those of traditional economics [37]. In our study, the interaction between supply and demand can be reflected through the total of individual interactions in the bicycle-sharing market. In fact, this can be demonstrated by the rules for matching supply with demand through agents, as shown in Figure 2. In this sense, our explanation of membership dynamics follows the structure of "Coleman's boat" theory, which emphasizes that the causal relationships between two macro-level phenomena require the specifications of a macro-micro-macro causal 
chain $[38,39]$, as the theoretical basis for the research on macroscopic emerging rules that are based on the interactive relationship between microcosmic action subjects.

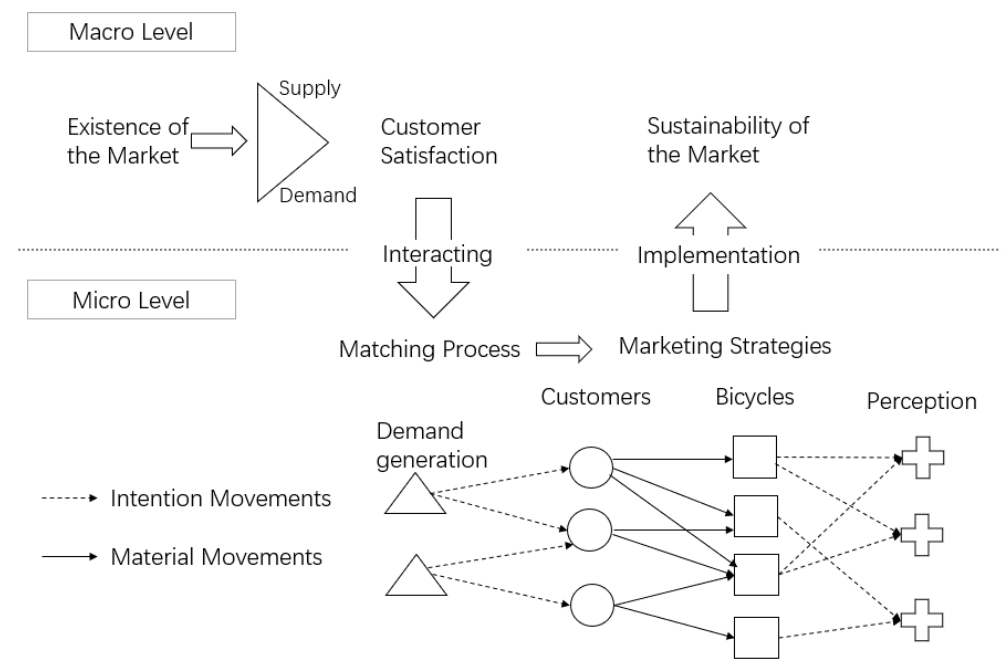

Figure 2. Conceptual framework describing the sustainability of the bicycle-sharing market. Note: circle refers to the customer, which is matched to the bicycles (square). The cross is the perception of each customer. The number of shapes is just a schematic expression.

At the micro-level, the existence of the market relies on the matching process of demand and supply, particularly the strategies to improve market efficiency. We analyze the sustainability of the bicycle-sharing market at the macro-level from the emerging rules with the macro-micro-macro causal chain shown in Figure 2.

\section{Model Framework and Implementation}

\subsection{The Assumptions of a Bicycle-Sharing System with Sustainability}

In the current study, we studied the interactivity between supply and demand when the two sides were informed with limited information in a simulated bicycle-sharing market. Based on the characteristics and logic of the bicycle-sharing market, we assumed that (1) in the bicycle-sharing market, the bicycle-sharing service involves randomness, whereby demands randomly emerge on the forwarding process when matched by supply; (2) dynamic adaptation can be seen in the interactions between demand and supply; and (3) micro-level market system dynamics give rise to specific patterns of supply or demand growth and decline. In the current study, the interactions between supply and demand are simulated using two processes of market generating. The models are set out below Figure 3.

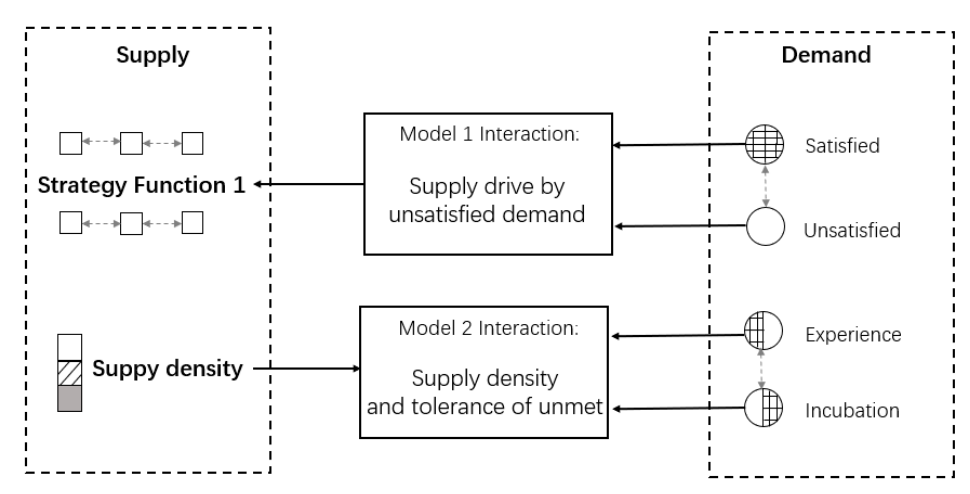

Figure 3. Interaction process of supply and demand in the estimated bicycle-sharing market system. 
Unlike Uber, whose users search for a service and get accurate matching through the internet, which generates a large amount of data for analysis, the matching process of sharing bicycles is on the road. To determine the interactions between the supply of bicycles and the demands of users, it is imperative to complete a simulation and abstraction of the operation mode of bicycle-sharing using real situations. Accordingly, the following strategies for promoting the emergence of the sustainability of the bicycle-sharing market were investigated in the model:

- Crossing-by matching (CM) describes a pattern for meeting the demand for bicycle-sharing. According to the models of OFO and Mobike in China, users usually need a bicycle while on the move. However, users will choose other means of transportation if no bike-sharing services are found, in which case they can still move around without difficulty. With that in mind, it is fair to say that the bicycle-sharing service involves randomness. The commuters can take the bicycles whenever they need them and leave them behind when they reach their destination [40].

- The fixed-time (FT) aspect of bicycle riding describes the range in terms of travel time where bicycles are more competitive than other modes of transport; in urban areas, this is between 2 and $8 \mathrm{~min}$ [41]. Non-motorized transport modes such as cycling are environmentally friendly, cheap, and reasonably fast alternatives for trips up to $3.5 \mathrm{~km}$ [42]. A substantial proportion of passengers in the train system commute a short distance-more than $16 \%$ of passengers alight within two stops from their origin - which forms a latent segment of demand for a bicycle-sharing program [43]. The cycle time of sharing bicycles is in the same range.

- Customer satisfaction determines the willingness to use the service again. Utility, trust, cost savings, and familiarity were found to be essential in previous studies [44]. Customer loyalty was considered as both attitudinal commitment and behavioral re-purchase intention [45]. The industry should try improving customer satisfaction management (CSM) and meeting the transportation needs of users-a key issue that must be solved for the bicycle-sharing market to survive.

Furthermore, the strategies employed by supplier agents promote the satisfaction of the demand agents. In Model 1, an increasing supply is used to meet the demands of the bicycle-sharing market. This intends to provide better user satisfaction by referring to whether users were satisfied the previous time. In Model 2, the relationship between the density of the supplier agent and the tolerance of unmet customer demands is examined. The other basic assumptions of Model 2 are as follows:

- The early period of product service input can also be termed the market probation period for demand, during which users review the overall experience and comment on the product service before deciding whether to continue using it in the future.

- Users will quit the market once their basic requirements are not met within the probation period, in which case they will stop using the product or service.

- The basic requirements are tantamount to the users' estimation of how effectively the product service is going to meet their demands; after all, a supply rate must be ensured for the requirement space to maintain users after the experience period ends. We term this as tolerability, and its relationship with the supply rate is a crucial factor that was studied through simulation experiments.

\subsection{Agents and Their Properties}

There are two types of agents involved in the estimated bicycle-sharing system: supplier agents (bicycle-sharing) and demand agents (customers).

\subsubsection{Supplier Agents}

Supplier agents are the shared bicycles put into the market to meet the needs of the demand space. Based on the above discussion, we further declared the properties and related parameters as shown in Table 1. 
Table 1. The properties of the supplier agent $\mathrm{i}(\mathrm{i}=1,2, \ldots, \mathrm{M})$.

\begin{tabular}{cll}
\hline Label & \multicolumn{1}{c}{ Name } & \multicolumn{1}{c}{ Description } \\
\hline BS & Bicycle-sharing status & $\begin{array}{l}\text { The BS determines the status of the shared bicycle: either S1 (sharing) } \\
\text { or S2 (idle) in each time slot. The bicycle can be shared when it has } \\
\text { idle status. }\end{array}$ \\
SI & Sharing income & $\begin{array}{l}\text { This is the sum income gained from the shared bicycle, i.e., the } \\
\text { cumulative amount of revenue per simulation time slot from T0 up to } \\
\text { the current time. }\end{array}$ \\
\hline NS & New sharing & $\begin{array}{l}\text { The newly generated suppliers in Tn are driven by the unsatisfied } \\
\text { demand in Tn }-1 \text { with a functional relationship, NS } \mathrm{n}=\mathrm{F} \text { (US n }-1) .\end{array}$ \\
\hline SUpro & Supply utilization rate & $\begin{array}{l}\text { SUpro (SUpro } \in[0,1]) \text { is the proportion of customers using shared } \\
\text { bicycles in Tn. SUpro reflects the utilization of supplies. }\end{array}$ \\
\hline SD & Supply density & $\begin{array}{l}\text { SD (SD } \in[0,1]) \text { is the supply density of the shared bicycles, reflecting } \\
\text { the occupation degree of market demand space. }\end{array}$ \\
\hline
\end{tabular}

Note: $\mathrm{M}$ refers to the total number of supplier agents, Tn refers to the specific simulation time slot, US $\mathrm{n}-1$ refers to the unsatisfied demand of $n-1$ time slot.

\subsubsection{Demand Agents}

In the current research on the bicycle-sharing market, demand agents are customers who are moving around in the simulation market space. When a suitable level of supply is encountered, they will occupy the bicycle for some time. Otherwise, they will continue moving forward. We further declared the properties and related parameters as shown in Table 2.

Table 2. The properties of the demand agent $i(i=1,2, \ldots, K)$.

\begin{tabular}{ccl}
\hline Label & \multicolumn{1}{c}{ Name } & \multicolumn{1}{c}{ Description } \\
\hline CS & $\begin{array}{c}\text { Customer sharing } \\
\text { status }\end{array}$ & $\begin{array}{l}\text { CS determines the status of the customers in the bicycle-sharing } \\
\text { market space: D1 (sharing), D2 (non-sharing), or D3 (quit the market). }\end{array}$ \\
\hline SR pro & Customer satisfied rate & $\begin{array}{l}\text { SUpro (SUpro } \in[0,1]) \text { is the proportion of the customers whose } \\
\text { demands are satisfied in the certain Tn time slot, reflecting the degree } \\
\text { to which the supply is meeting the market needs. }\end{array}$ \\
\hline CP & Customer probation & $\begin{array}{l}\text { CP determines the time from T0 to the end of the probation period, } \\
\text { in which customers summarize the overall perceived impression of } \\
\text { using the bicycle-sharing service. }\end{array}$ \\
\hline RT & Rate of tolerance & $\begin{array}{l}\text { RT (RT } \in[0,1]) \text { is the percentage of customer use of bicycle-sharing in } \\
\text { Tn. SUpro reflects the utilization of supplies. }\end{array}$ \\
\hline LR pro & Living rate & $\begin{array}{l}\text { LR pro (LR pro } \in[0,1]) \text { is the proportion of living customers after the } \\
\text { probation period who have not withdrawn from the market. }\end{array}$ \\
\hline
\end{tabular}

Note: $\mathrm{K}$ refers to the total number of demand agents, Tn refers to the specific simulation time slot.

\subsection{Interaction and Influence Dynamics}

In ABM research, intelligent agents adjust their behavior and update their properties according to the environment and interactions with other agents [46]. In the current simulation, two agents can only interact with each other when there is a link between them.

In the potential demand space, a step-by-step outline of the algorithm was done for Models 1 and 2 , respectively. The simulation started at $\mathrm{T}=0$, and terminated when the demand and supply levels converged with time to move into the stability status. 


\subsubsection{Movement of Customer Demand}

In the potential demand space, the location of supply is relatively fixed. Demand may be constantly changing according to the travel conditions.

$$
\left(x_{i}(t), y_{i}(t)\right)=\left(x_{i}(t-1), y_{i}(t-1)\right)+\left(\Delta x_{i}(t-1), \Delta y_{i}(t-1)\right) \cdot \alpha
$$

As shown in Equation (1), $\left(x_{i}(t), y_{i}(t)\right)$ is the demand coordinate position of customer agent $i$ at time slot $t$. $\left(\Delta x_{i}(t-1), \Delta y_{i}(t-1)\right)$ reflects the demand mobility vector of customer agent $i$ at time slot $t-1$, and $\alpha$ is the stochastic quantity of demand change. During the process of demand mobility, when coming across a suitable supply, the demand agent will change its status accordingly.

\subsubsection{Interactions between Supply and Demand}

Each round of the simulation of interactions between supply and demand has three steps: firstly, the supply-demand status of the bicycle-sharing market space is updated; secondly, the demand agents use bicycles while moving forward; thirdly, the amount and distribution of new supplies is determined in accordance with the satisfaction level of users at the previous time slot. How these steps are invoked is determined by the specific rates set under different simulation conditions, as shown in Figure 4.

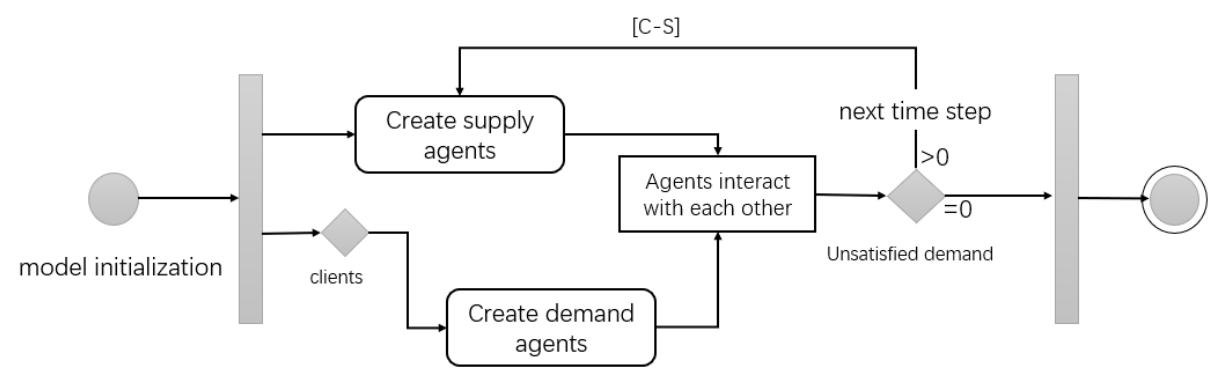

Figure 4. Simulation process of interactions between supply and demand.

In the interactions between supply and demand, the newly generated suppliers in Tn are driven by unsatisfied demand in Tn -1 through the customer-sharing procedure in Figure 3, with a functional relationship as per Equation (2).

$$
\mathrm{S}(t)=\mathrm{S}(t-1)+\delta \cdot(1-\mathrm{SRpro}) \cdot K \cdot(t-1),
$$

where $(1-$ SRpro $)$ is the unsatisfied rate of the demand in the Tn time slot, $K$ is the total amount of demand agents, and $\delta$ reflects the quantity and distribution mode of the newly generated suppliers.

\subsubsection{Interactions between the Supply Density and Tolerance of Unmet Demands}

The current model includes an interaction between the supply density and tolerance of unmet demands through the introduction of the probation period. According to relationship marketing theory [47], a customer's "lifetime" (period of tenure with the firm) is determined by the length of the probationary period and the criterion for continuation, which represents the potential value of a customer to a commercial organization [48]. How interactions are invoked is determined by the specific parameters set under the different simulation conditions shown in Figure 5. 


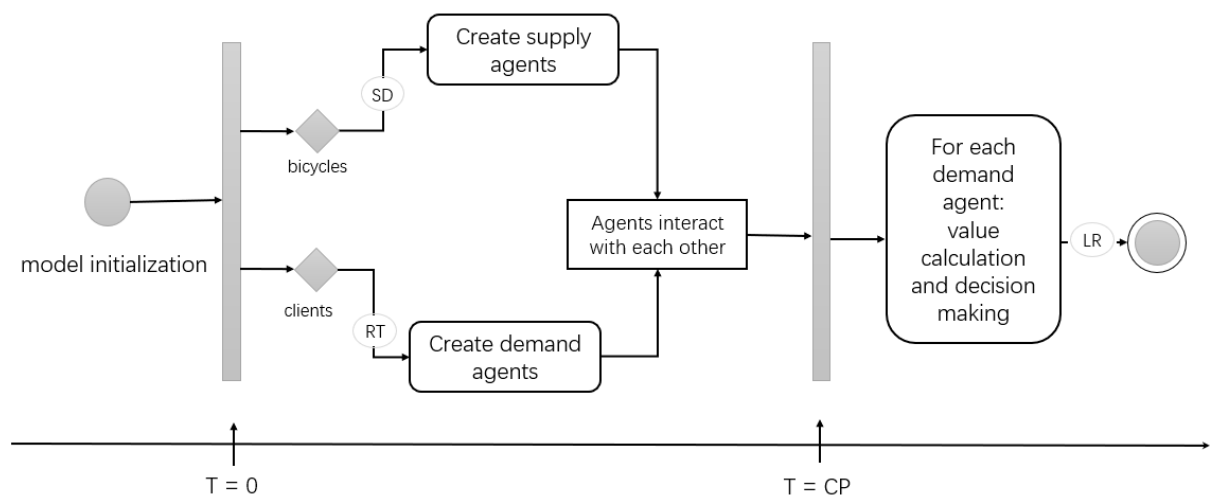

Figure 5. Simulation process of interactions between the supply density and the tolerance of unmet demands.

As shown in Figure 5, at the end of the probation period, each demand agent evaluates their rate of satisfaction and compares it with their rate of tolerance before updating their sharing status (CS) accordingly.

$$
\mathrm{CS}_{\mathrm{D} 3 \mathrm{ij}}=\left\{\begin{array}{ll}
1 & \sum_{t=0}^{t=C P j} \text { wijt } / C P j<R T j \\
0 & \sum_{t=0}^{t=C P j} \text { wijt } / C P j \geq R T j
\end{array} .\right.
$$

To explore the laws of the interaction between the supply density and the tolerance of unmet demands, we investigated the interaction process under different parameter combinations. In Equation (3), $j$ is the order number of experiments, and wijt reflects the demand agent $i$ sharing its status at time slot $t$ in experiment $j$.

\subsection{Implementation}

Netlogo 6.0.1 was selected as the experimental platform, and the interactions between agents were achieved through coding and a designed ABM. The Netlogo interface of the proposed bicycle-sharing system (Model 1) is shown in Figure 6. The simulation environment was designed as a $32 \times 32$ ( $N=1024)$ demanding space. We used the sliders to adjust the initial parameters of the model, and the charts and monitors to reflect the dynamic changes of agents. The interactions and behaviors of the agents are displayed in the interface.
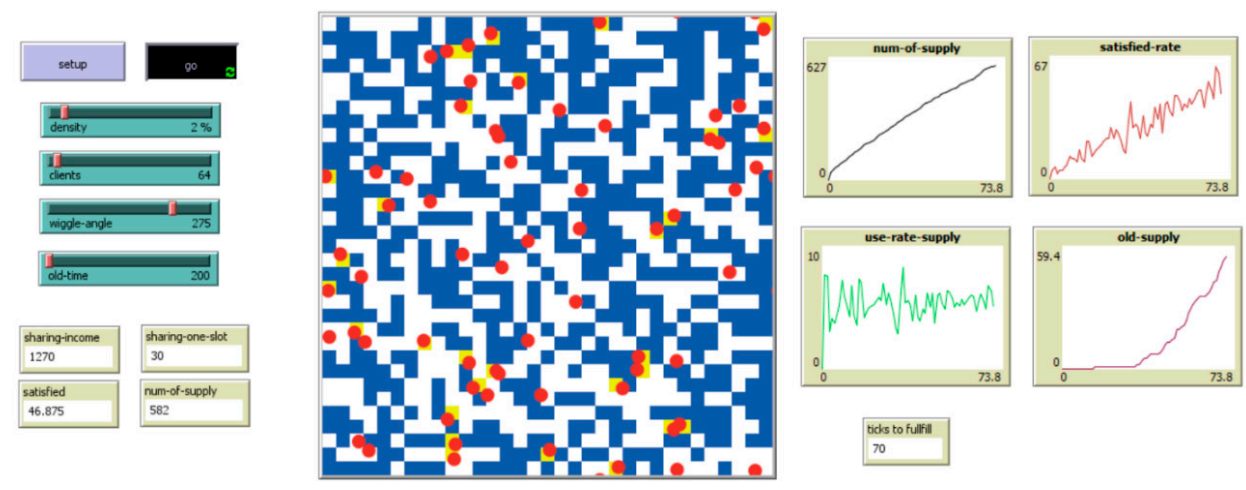

Figure 6. The simulation interface for the interactions between supply and demand in Model 1.

\section{Results and Analysis}

For each model, we conducted an experiment repeatedly 20 times, and used the average results to study the relationship between supply and demand in the bicycle-sharing market. 


\subsection{The Suppliers Drive by Demands: Excessive Supplement}

The simulation experiments found that the bicycle-sharing market is inclined to provide a supplement to the current supply level, depending on how much user demand is not satisfied, to increase the overall satisfaction. The magnitude of bicycle supply continued rising with time, and, at $\mathrm{T}=150$, the distribution density in the market space far exceeded that at $\mathrm{T}=0$. The trends generated by the changes in the bicycle-sharing world are depicted in Figure 7.
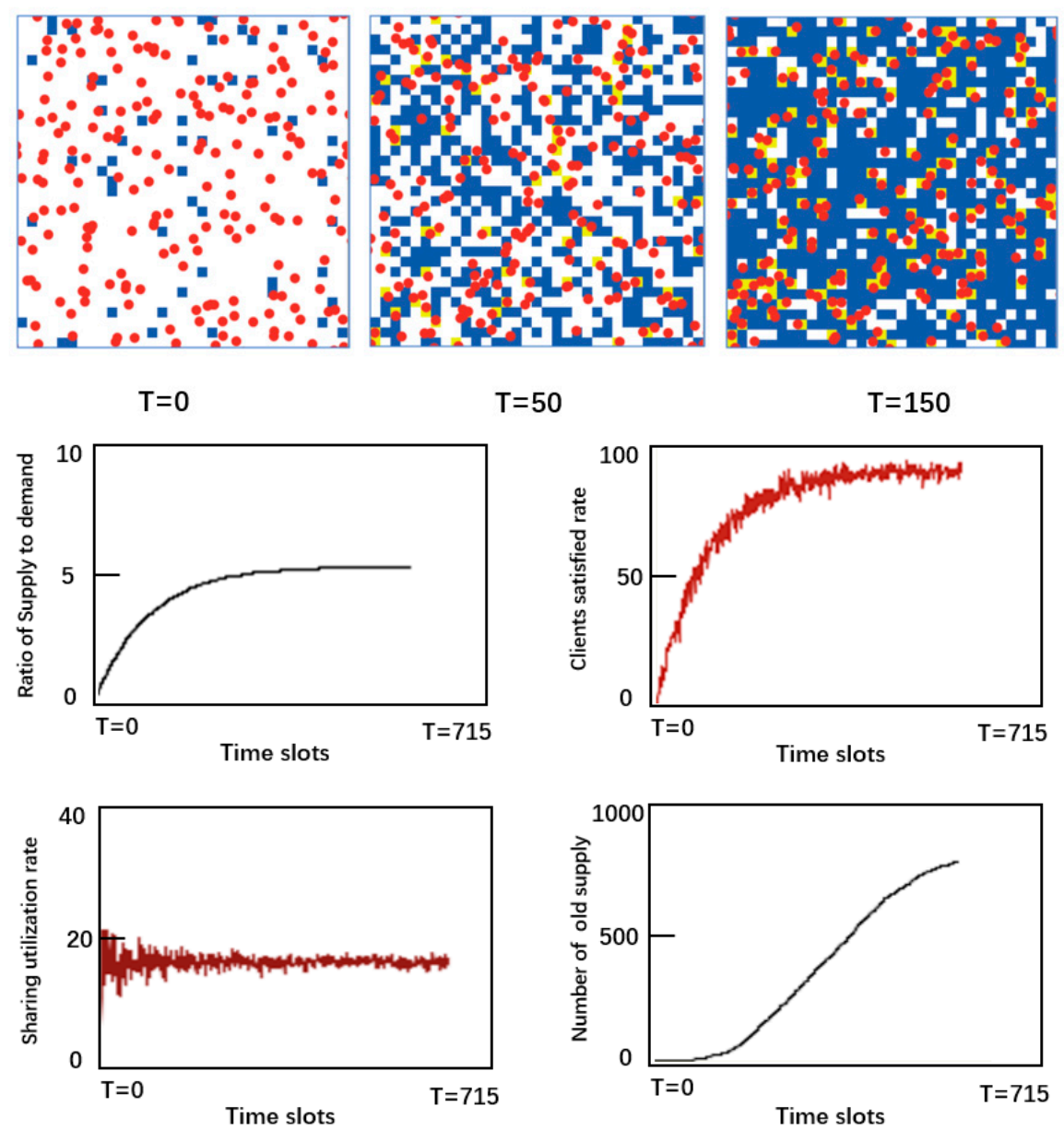

Figure 7. Evolutionary trends of interactions between demand and supply in Model 1. Note that the changes in the graphical interface show that the supply density of the market increased with time. Four parameters reflect the efficiency of the market system, which converge gradually to a stable state after the supply is saturated.

As the supply increased, the degree of user satisfaction also increased, but the rate of increase in user demand satisfaction appeared to slow gradually as it approached $100 \%$-the highest level of user demand satisfaction. However, to achieve a high user demand satisfaction level, a guarantee of high supply was also shown to be needed, with the amount of supply being much higher than the demand.

During this simulation, when the user satisfaction converged toward stability, the supply-demand ratio also gradually rose until the ratio of supply to demand at saturation time was equal to 5.34 (supply/demand $=5.34$ ). As the supply increased, the usage rate of the sharing products in the sharing market system demonstrated a highly turbulent trend in the early stages of the simulation. As the interaction process proceeded, the usage rate gradually moved toward a stable value. 


\subsection{The Influence of the Customer Probation Period}

With respect to Model 2, the effects of the supply density on the level of user demand satisfaction were analyzed under a fixed level of demand. Previous research stated that a lifecycle exists for every user's acceptance of a certain product or service [49,50]. The formation of usage habits on certain services requires a specific amount of time for the nurturing process to occur; hence, customer loyalty is very essential in terms of the creation of long-term values [51]. This implies that it is important for the providers of products and services to invest time into constructing a network of connections with their customers [52]. This condition also applies to the bicycle-sharing market; during the early introductory stages of the products or services, a period must be allocated to nurture and cultivate the customers' usage habits and degree of loyalty. Should the product or service provider fail to establish strong and sufficiently intimate networks of connections with their respective customers, these customers will naturally leave the market, and even decide to discontinue their usage of the products or services.

This experiment studied the relationship between the degree of tolerance toward a certain product or service that did not fully meet the user's satisfactory levels during a certain nurturing period, where the actual supply rate was provided by the product or service supplier. Figure 8 shows that, when a user's tolerance levels was $50 \%$, the levels of demand and supply densities in the sharing market, with respect to the corresponding trends in the user demand satisfaction curve, can be divided into three levels: high, medium, and low.

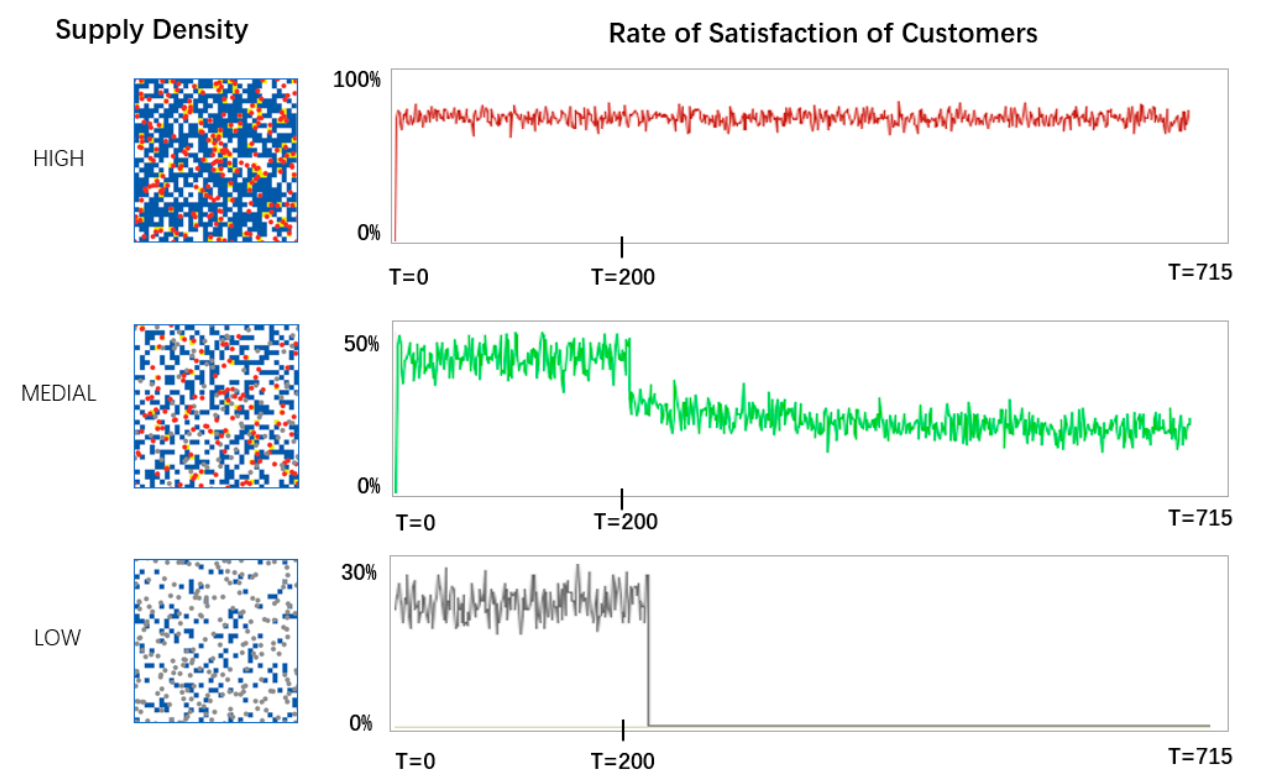

Figure 8. Evolutionary trend of interactions between demand and supply in Model 2. Note that the red dots represent active customers, the blue squares are free bicycles, the yellow squares are shared bicycles, and the grey dots represent customers who left the service. The red line is the market for all active users, the green line is the market for the portion of active users, and the grey line is the failed market without active users.

This implies that, in the case of user with medium tolerance levels, when the supply density is low, if the overall user experience is lower than the tolerance threshold during the period of product and service testing, it can be concluded that, at the end of the testing period, the user will quit the market, and the provider will completely lose its competence in the market.

If the supply density is medium, a portion of the users will quit the market after the testing period. Despite still being able to retain some part of the demand, the provider's efficiency in the market will be significantly lowered. Finally, our experiment also presented that high levels of supply density were beneficial to the continuity and sustainability of the demand for products or services in the market. 


\subsection{The Threshold of Supply Density Required to Maintain the Market}

Simulations confirmed the role of supply density in market persistence, as previous research confirmed that an expanding system size increases its performance [53]. At the end of the probation period, the existence of the market completely depends on the supply density of the supplier and the tolerance levels of the customers. It can be observed from the simulation process that, by raising the levels of supply density of products or services, the corresponding increase in demand retention rate in the market can be significantly guaranteed. However, the correlation between supply rate and demand retention rate is not a positive linear trend, but rather, an obvious threshold value exists whereby, other than the supply rate threshold, the demand retention rate must demonstrate an opposite, paradoxical, and contradicting behavior.

As shown in Figure 9, under a certain level of customer tolerance, the supply density of the bicycle-sharing market is governed by a tolerance range below which the provider will completely lose all demand at the end of the probation period, and the bicycle-sharing market will disappear. If the supply density is above that of the threshold's upper limit, at the end of the probation period, all the demand will be retained, and the bicycle-sharing market will persist.

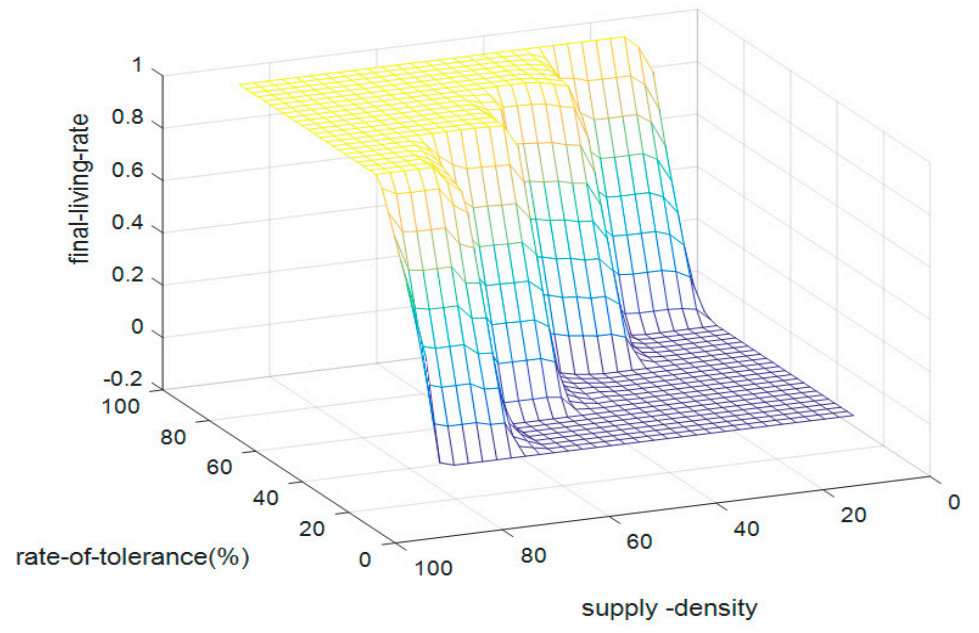

Figure 9. The relationship between the rate of tolerance, the supply density, and the final living rate. Note that the supply density threshold range differs with different clients' tolerance levels.

An important finding in the current study was the threshold of supply density under a specific demand tolerance level. The threshold is a widespread social and systemic phenomenon [54], which indicates that the sustainable existence of China's bicycle-sharing market should find and satisfy the supply density under specific market characteristics.

\subsection{Discussions of Results}

In the estimated bicycle-sharing market system, by making reflections on the experimental simulation with two demand-and-supply interaction models, we derived several conclusions.

The bicycle-sharing market is governed by a set of objective laws that naturally require an oversupply of the product. In other words, a high user satisfaction can be reached if and only if the supplier of shared bicycles launched far exceeds the quantity of the actual or potential demand. The simulation results showed that supply has a multiplier effect relative to the demand, which means that demand will generate much more supply in the current bicycle-sharing system of China.

The current research suggests that the higher a user's tolerance for unsatisfied demands during a probation period is, the lower the required minimum limit or threshold value of supply density for maintaining the user retention rate is. User habits and market attitudes are also important influential factors in market persistence. 
The width of the supply density threshold range differs with different tolerance levels; lower tolerance levels translate to a narrower supply density threshold range. The threshold range has a certain degree of elasticity. Therefore, the determination of a market retention supply density threshold range is crucial when determining whether it is plausible to achieve the minimum supply density for the sustainable development of the bicycle-sharing market under the circumstances of ensuring market sustainability and reducing the uncertainty of bicycle-sharing suppliers.

The simulation results showed that, in the sharing-bicycle market, the supply must be 5.34 times the demand to be able to achieve total satisfaction of the demand, and a large volume of demand will give rise to larger scale of supply. Therefore, a city with a larger population has a more severe oversupply of sharing-bicycles. The sustainability in the market depends on the habit development of the users; if a product cannot meet the demand of the users as much as possible at the initial stage of its entry into the market, it will lose customers. Model 2 showed that there is a critical supply density in the bicycle-sharing market, the value of which depends on the customers' use habit that may be correlated with the culture; once the density is below the critical value, the sharing-bicycle market will no longer exist.

\section{Conclusions and Suggestions}

The sustainable development of a sharing economy is yet to be fully evaluated [55]. The objective of this paper was to make contributions to illuminate the supply characteristics of the bicycle-sharing market using agent-based modeling, and to conduct a discussion on its sustainable development in China. Due to the large urban population, a more serious oversupply problem will occur in China's bicycle-sharing market, a problem that occurred in its early development stage. The problem of excessive supply is an issue for urban traffic. However, once the supply is controlled to below the threshold, the demand will diminish, and the market will disappear.

This paper also explored how the relevant departments of the government and bicycle-sharing industry should cope with the challenges related to oversupply, and the balance between overflooding and the market vanishing. Policy-makers should recognize the importance of bicycle-sharing to allow the characteristics of these public goods to be valued and to reduce the market attribute of bicycle-sharing. Therefore, the government should play a leading role in designing reasonable regulations to solve these problems. According to the results and conclusions of the current study, the key aspects of the sustainable development of the bicycle-sharing market are twofold: firstly, the reliability of supply needs to be improved and, secondly, the uncertainty in demand needs to be reduced.

Policy-makers should also establish some standards for entering the industry and should supervise the operation of the market. Standardizing the distribution of shared bicycles and fixing their locations could solve the disorder brought by excessive supply. The Chinese government has started attaching more importance to the management and standardization of this newly developing industry in China [56].

The foundation of the bicycle-sharing market is none other than the internet and information systems. Data management and information transmission are accomplished by a network platform to track the actual operations of bicycle-sharing. When users spot bicycles that meet their transportation needs on the move, they can register, authenticate, submit a guarantee deposit, and use bicycles with their smartphones. Meanwhile, the relevant information is sent to the network platform for data updates, appointments, tracking, and scheduling, all of which are transmitted between the bicycles and the network platform. The success of the bicycle systems depends on the network of bicycle paths and the locations of stations where the bicycles can be picked up and returned [40]. Public bicycle-sharing needs to be carefully developed to appreciate the quality and timely interplay between the physical design of the system and the provision of services being offered. Therefore, industrial practitioners should conduct in-depth mining of the large amount of user data owned by the platform [57]. 
The massive amounts of data involved in the transactions of the bicycle-sharing system are essential for solving the underlying issues of the bicycle-sharing market and can be used to predict future travel behavior to reduce the level of uncertainty. Resource scheduling based on demand forecasting may provide a long-lasting mechanism to ensure that the customers' lifetime value of bicycle-sharing can be established. Moreover, with the help of a big data-based intelligent and comprehensive dispatch system, the issue of oversupply in the bicycle-sharing market can be effectively mitigated. On this basis, the supply of shared bicycles can be regulated and allocated comprehensively to improve the level of resource utilization. For industrial practitioners, customer tolerance of the bicycle-sharing market can be improved by publicly emphasizing its green environmental value [19].

Future studies are encouraged to conceptualize the property rights of sharing economics, to incorporate more detailed models to explore the behaviors of supply and demand agents in the bicycle-sharing system, and to incorporate more environmental factors into the simulations. In addition, the model design in the current study can be applied to explore the characteristics of similar sharing economic markets.

Author Contributions: X.C. performed the theory analysis and coding, and contributed to drafting the manuscript. Q.Q. improved the empirical analysis and writing. M.-H.C. improved the writing and conclusions. S.F.F. analyzed the data. Y.C. checked the writing.

Funding: The research for this paper was supported by the National Social Science Foundation of China (No. 15CSH017), the National Natural Science Foundation of China (No. 71801047), the Beijing Philosophy and Social Sciences Planning Project (No. 17GLC052), Beijing Municipal Science and Technology Project (Grant No. D171100003317001), UIBE Excellent Young Scholar (No. 18YQ12), and the Dong Lu youth scholar training project of Yunnan University (No. C176220200).

Acknowledgments: We are grateful for the contributions to and inspiration for the research method from Yu Cheng Liang and Yong Ren Shi, as well as participants in the 2017 workshop on artificial society and computational social sciences, at the School of Sociology and Anthropology, Sun Yat-sen University. We are grateful for the editor and comments from anonymous reviews. All remaining errors are strictly the responsibility of the authors.

Conflicts of Interest: The authors declare no conflicts of interest.

\section{References}

1. Zhang, L.; Zhang, J.; Duan, Z.Y.; Bryde, D. Sustainable bike-sharing systems: Characteristics and commonalities across cases in urban China. J. Clean. Prod. 2015, 97, 124-133. [CrossRef]

2. Hamari, J.; Sjöklint, M.; Ukkonen, A. The sharing economy: Why people participate in collaborative consumption. J. Assoc. Inf. Sci. Technol. 2016, 67, 2047-2059. [CrossRef]

3. Belk, R. You are what you can access: Sharing and collaborative consumption online. J. Bus. Res. 2014, 67, 1595-1600. [CrossRef]

4. Ranchordas, S. Does Sharing Mean Caring? Regulating Innovation in the Sharing Economy. Soc. Sci. Electron. Publ. 2015, 16, 413-475.

5. Liu, Y.; Xia, J.C. Research trends in shared economic theory and policy. Econ. Perspect. 2016, 4, 116-125. (In Chinese)

6. Shaheen, S.; Guzman, S.; Zhang, H. Bikesharing in Europe, the Americas, an Asia: Past, Present, and Future. In Proceedings of the Transportation Research Board Annual Meeting, Washington, DC, USA, 15 March 2010.

7. Yang, S. Sharing Economy Types, Factors and Influences: The Perspective of Literature Research. Rev. Ind. Econ. 2016, 2, 35-45. (In Chinese)

8. Palos-Sanchez, P.R.; Correia, M.B. The Collaborative Economy Based Analysis of Demand: Study of Airbnb Case in Spain and Portugal. J. Theor. Appl. Electron. Commer. Res. 2018, 13, 85-98. [CrossRef]

9. Barth, M.; Shaheen, S. Shared-use vehicle systems: Framework for classifying carsharing, station cars, and combined approaches. Transp. Res. Rec. J. Transp. Res. Board 2002, 1791, 105-112. [CrossRef]

10. Qin, Z.; Wang, Q. Sharing economic deductive three-party cooperative mechanism: Example sharing single car. Reform 2017, 5, 124-134. (In Chinese)

11. Li, X.H. Ten Ministries and Commissions Established New Rules and Regulations, Can the Barbaric Growth of Sharing Bicycles Be Controlled? Available online: http:/ / news.sohu.com (accessed on 10 August 2017). 
12. Zhou, Q.R. What are the difficulties of sharing the economy? Beijing Daily, 13 May 2017. (In Chinese)

13. Wei, H.; Fan, W.; Wang, X.; Lu, N.; Dong, X.; Zhao, Y. Integrating supply and social demand in ecosystem services assessment: A review. Ecosyst. Serv. 2017, 25, 15-27. [CrossRef]

14. Song, Y.; Wang, Y. Sharing Economy: Origin, Definition and Influence. Teach. Res. 2016, 9, 29-36. (In Chinese)

15. Yin, J.; Qian, L.; Singhapakdi, A. Sharing sustainability: How values and ethics matter in consumers' adoption of public bicycle-sharing scheme. J. Bus. Ethics 2018, 149, 313-332. [CrossRef]

16. Mugion, R.G.; Toni, M.; Raharjo, H.; Di Pietro, L.; Sebathu, S.P. Does the service quality of urban public transport enhance sustainable mobility? J. Clean. Prod. 2018, 174, 1566-1587. [CrossRef]

17. Vezzoli, C.; Ceschin, F. Product Service Systems in the automotive industry: An alternative business model for a sustainable satisfaction system. In Proceedings of the Sixth International Conference on Manufacturing Research (ICMR08), London, UK, 9-11 September 2008; pp. 549-556.

18. Bordagaray, M.; Ibeas, A.; dell'Olio, L. Modeling user perception of public bicycle services. Procedia-Soc. Behav. Sci. 2012, 54, 1308-1316. [CrossRef]

19. Wang, Y.; Douglas, M.A.; Hazen, B.T.; Dresner, M. Be green and clearly be seen: How consumer values and attitudes affect adoption of bicycle sharing. Transp. Res. Part F Traffic Psychol. Behav. 2018, 58, 730-742. [CrossRef]

20. Kaplan, S.; Wrzesinska, D.K.; Prato, C.G. The role of human needs in the intention to use conventional and electric bicycle sharing in a driving-oriented country. Transp. Policy 2018, 71, 138-146. [CrossRef]

21. Leismann, K.; Schmitt, M.; Rohn, H. Collaborative Consumption: Towards a Resource-Saving Consumption Culture. Resources 2013, 2, 184-203. [CrossRef]

22. Cheng, M. Sharing economy: A review and agenda for future research. Int. J. Hosp. Manag. 2016, 57, 60-70. [CrossRef]

23. Ranchordás, S. Does sharing mean caring: Regulating innovation in the sharing economy. Minn. J. Law Sci. Technol. 2015, 16, 413.

24. Guo, Q.Z. Can the sharing bicycles market fly? Internet Econ. 2016, 11, 16-19.

25. Hardin, G. The Tragedy of the Commons. Science 1968, 162, 1243-1248. [CrossRef] [PubMed]

26. Coase, R.; North, D. Property Rights and Institutional Changes; Shanghai Joint Publishing House: Shanghai, China, 1990.

27. Tesfatsion, L. Agent-based computational economics: Modeling economies as complex adaptive systems. Inf. Sci. 2003, 149, 262-268. [CrossRef]

28. Shi, Y.R.; Gao, L.; Zhang, J. Agent-Based Computational Economics and its Application in Supply Networks. Complex Syst. Complex. Sci. 2006, 3, 69-76. (In Chinese)

29. Howitt, P.; Clower, R. The emergence of economic organization. Soc. Sci. Electron. Publ. 2004, 41, 55-84. [CrossRef]

30. Macy, M.; Willer, R. From Factors to Actors: Computational Sociology and Agent-Based Modeling. Ann. Rev. Sociol. 2002, 28, 143-166. [CrossRef]

31. Dijkema, G.P.; Basson, L. Complexity and industrial ecology: Foundations for a transformation from analysis to action. J. Ind. Ecol. 2009, 13, 157-164. [CrossRef]

32. Tesfatsion, L. Agent-Based Computational Economics: Growing Economies from the Bottom Up. Artif. Life 2014, 8, 55-82. [CrossRef] [PubMed]

33. Farmer, J.D.; Foley, D. The economy needs agent-based modelling. Nature 2009, 460, 685-686. [CrossRef] [PubMed]

34. Zhu, Q.; Duan, K.; Wu, J.; Wang, Z. Agent-based modeling of global carbon trading and its policy implications for china in the post-Kyoto era. Emerg. Mark. Financ. Trade 2016, 52, 1348-1360. [CrossRef]

35. Arthur, W.B.; Holland, J.H.; Lebaron, B. Asset Pricing Under Endogenous Expectations in an Artificial Stock Market. Soc. Sci. Electron. Publ. 1998, 23, 1487-1516.

36. Epstein, J.M.; Axtell, R. Growing Artificial Societies: Social Science from the Bottom Up; Bradford Book: Washinton, DC, USA, 1996.

37. Schor, J. Debating the Sharing Economy. J. Self-Gov. Manag. Econ. 2016, 3, 7-23.

38. Coleman, J.S. Foundations of Social Theory; Harvard University Press: Cambridge, MA, USA, 1990.

39. Boons, F.; Spekkink, W. Levels of institutional capacity and actor expectations about industrial symbiosis: Evidence from the Dutch stimulation program 1999-2004. J. Ind. Ecol. 2012, 16, 61-69. [CrossRef] 
40. Lin, J.R.; Yang, T.H. Strategic design of public bicycle sharing systems with service level constraints. Transp. Res. Part E Logist. Transp. Rev. 2011, 47, 284-294. [CrossRef]

41. Frade, I.; Ribeiro, A. Bicycle sharing systems demand. Procedia-Soc. Behav. Sci. 2014, 111, 518-527. [CrossRef]

42. Rietveld, P. Non-motorised modes in transport systems: A multimodal chain perspective for The Netherlands. Transp. Res. Part D Transp. Environ. 2000, 5, 31-36. [CrossRef]

43. Shu, J.; Chou, M.C.; Liu, Q.; Teo, C.P.; Wang, I.L. Models for effective deployment and redistribution of bicycles within public bicycle-sharing systems. Oper. Res. 2013, 61, 1346-1359. [CrossRef]

44. Möhlmann, M. Collaborative consumption: Determinants of satisfaction and the likelihood of using a sharing economy option again. J. Consum. Behav. 2015, 14, 193-207. [CrossRef]

45. Lin, H.H.; Wang, Y.S. An examination of the determinants of customer loyalty in mobile commerce contexts. Inf. Manag. 2013, 43, 271-282. [CrossRef]

46. Zheng, K.; Jia, S. Promoting the Opportunity Identification of Industrial Symbiosis: Agent-Based Modeling Inspired by Innovation Diffusion Theory. Sustainability. 2017, 9, 765. [CrossRef]

47. Möller, K.; Halinen, A. Relationship marketing theory: Its roots and direction. J. Mark. Manag. 2000, 16, $29-54$. [CrossRef]

48. Crowder, M.; Hand, D.J.; Krzanowski, W. On optimal intervention for customer lifetime value. Eur. J. Oper. Res. 2007, 183, 1550-1559. [CrossRef]

49. Berger, P.D.; Nasr, N.I. Customer lifetime value: Marketing models and applications. J. Interact. Mark. 1998, 12, 17-30. [CrossRef]

50. Borle, S.; Singh, S.S.; Jain, D.C. Customer lifetime value measurement. Manag. Sci. 2008, 54, 100-112. [CrossRef]

51. Jason, Q.; Zhang, A.D.; Roberto, F. Customer Loyalty and Lifetime Value: An Empirical Investigation of Consumer-Packaged Goods. J. Mark. Theory Pract. 2010, 18, 127-140.

52. Lewis, M. Customer Acquisition Promotions and Customer Asset Value. J. Mark. Res. 2006, 43, $195-203$. [CrossRef]

53. Chardon, C.M.D.; Caruso, G.; Thomas, I. Bicycle sharing system 'success' determinants. Transp. Res. Part A Policy Pract. 2017, 100, 202-214. [CrossRef]

54. Granovetter, M. Threshold models of collective behavior. Am. J. Sociol. 1978, 83, 1420-1443. [CrossRef]

55. Barnes, S.J.; Mattsson, J. Understanding current and future issues in collaborative consumption: A four-stage Delphi study. Technol. Forecast. Soc. Chang. 2016, 104, 200-211. [CrossRef]

56. Gu, D.S. "Encouragement" and "regulation": The administrative legal implication of sharing bicycle policy. Transp. Navig. 2017, 4, 8-12.

57. Lai, L.; Jiang, N.J. A Study on Business Model Design of Shared Bicycle Based on Ground Theory-A Case Study of Mobicycle. Contemp. Econ. Manag. 2017, 39, 19-22. 